\title{
Fasciodontia gen. nov. (Hymenochaetales, Basidiomycota) and the taxonomic status of Deviodontia
}

\author{
Eugene Yurchenko ${ }^{1}$ (D) - Janett Riebesehl ${ }^{2,3,4}$. Ewald Langer ${ }^{2}$
}

Received: 23 August 2019 / Revised: 29 December 2019 / Accepted: 30 December 2019

(C) German Mycological Society and Springer-Verlag GmbH Germany, part of Springer Nature 2020

\begin{abstract}
A new genus Fasciodontia is described to classify Xylodon bugellensis, known mostly from Europe, and one new species, F. brasiliensis, collected in Atlantic rainforests of Brazil. A new combination F. bugellensis is proposed and the lectotype for this taxon was selected. The genus is characterized by fascicles of skeletal-like hyphae in aculeal trama and thick-walled basidiospores. The generic concept was supported by Bayesian and Maximum Likelihood molecular phylogenetic reconstructions based on the ITS region and D1/D2 domains of 28S rRNA gene. The morphological distinctions between Lyomyces pruni and F. bugellensis (earlier considered as conspecific) and their phylogenetic independence are described and illustrated. Additionally, Deviodontia pilaecystidiata is put into the genus Kneiffiella; Hyphodontia mongolica is referred to synonyms of K. pilaecystidiata. The phylogenetic position of Hastodontia halonata, Kneiffiella alienata, and Lyomyces fimbriatus are discussed for the first time, and the new combination Lyomyces fimbriatus is introduced.
\end{abstract}

Keywords Agaricomycetes $\cdot$ Corticioid fungi $\cdot$ New genus $\cdot$ New species $\cdot$ Skeletal-like hyphae $\cdot$ Taxonomy

\section{Introduction}

The basidiomycetous genus Hyphodontia J. Erikss. was described by John Eriksson (1958), based on the generic type $H$. pallidula (Bres.) J. Erikss. A first phylogenetic tree, which included DNA sequences of Hyphodontia s.l. species (Larsson et al. 2006), showed that the genus is polyphyletic. Hjortstam and Ryvarden $(2002,2009)$ divided the genus into 14 segregate genera on the basis of

Section Editor: Yu-Cheng Dai

Eugene Yurchenko eugene_yu@tut.by

1 Department of Biotechnology, Polessky State University, Dnyaprouskai flatylii str. 23, BY-225710 Pinsk, Belarus

2 Department of Ecology, University of Kassel, Heinrich-Plett-Str. 40, DE-34132 Kassel, Germany

3 Institute of Soil Science, Leibniz University Hannover, Herrenhäuser Str. 2, DE-30419 Hannover, Germany

4 Institute for Plant Protection in Horticulture and Forests, Julius Kühn-Institute, Messeweg 11/12,

DE-38104 Braunschweig, Germany morphological features. Later, Riebesehl and Langer (2017) revised the system and reduced the number of genera to seven, considering phylogenetic results. Subsequently, the genera Lagarobasidium Jülich and Palifer Stalpers \& P.K. Buchanan were synonymized with Xylodon by Viner et al. (2018) and Riebesehl et al. (2019). Today, five genera are distinguished in Hyphodontia s.1.: Hastodontia (Parmasto) Hjortstam \& Ryvarden, Hyphodontia s.s., Kneiffiella P. Karst., Lyomyces P. Karst., and Xylodon (Pers.) Gray.

This study dealt with the species complex of Lyomyces pruni (Lasch) Riebesehl \& Langer and Xylodon bugellensis (Ces.) Hjortstam \& Ryvarden. Phylogenetic analyses demonstrate two different taxa for this complex, not belonging to sister groups. The new genus Fasciodontia is introduced to represent $X$. bugellensis and related taxa. One new species is described and illustrated: Fasciodontia brasiliensis. In addition, DNA sequences of Kneiffiella pilaecystidiata (S. Lundell) Jülich \& Stalpers, Hastodontia halonata (J. Erikss. \& Hjortstam) Hjortstam \& Ryvarden, and Lyomyces fimbriatus (Sheng $\mathrm{H}$. Wu) Hjortstam \& Ryvarden were obtained for the first time and resulted in two new combinations and in the synonymization of one species and one genus. 


\section{Materials and methods}

\section{Morphological study}

The morphology was studied on dried specimens, deposited in collections CFMR, GB, HAL, KAS, MSK, TFC (acronyms follow Index Herbariorum, http://sweetgum.nybg.org/science/ih) as main specimens or duplicates (dup.). Microscopic characters were studied and measurements were done in 3\% $\mathrm{KOH}$ solution (abbreviated below as $\mathrm{KOH}$ ); additionally, spores and crystals were examined in Melzer's reagent and spore cyanophily was checked in lactophenolcotton blue solution. For the determination of average spore length (L) and width (W), 30 spores randomly selected in squash preparations were measured. Spore quotient (Q) was calculated as length/width ratio for individual spores.

\section{Molecular study}

Pieces of dried basidiomata, about $2-3 \mathrm{~mm}^{2}$, were used for DNA extractions with the E.Z.N.A.® Fungal DNA Mini Kit (Omega Bio-Tek, VWR, USA). Two ribosomal DNA markers were chosen for amplifications: the internal transcribed spacer (ITS), including ITS1, 2, and 5.8S gene, and the D1/D2 domains of 28S. Different combinations of the following primers were used for ITS: ITS1-F (Gardes and Bruns 1993), ITS1, ITS2, ITS3, ITS4, ITS5 (White et al. 1990), and ALR0 (Collopy et al. 2001); and for 28S: NL1, NL4 (O'Donnell 1993), LR0R (Bunyard et al. 1996), and LR5 (Vilgalys and Hester 1990). The primer ALR0 was modified in one position (Riebesehl and Langer 2017). PCR products were purified with innuPREP PCRpure Kit (Analytik Jena, Berlin, Germany) and the DNA sequencing was implemented by Eurofins Genomics (Ebersberg, Germany).

Newly generated sequences were edited with MEGA7 (Kumar et al. 2016) and deposited in NCBI GenBank (Benson et al. 2018; Tab. 1) after a quality check following the five guidelines by Nilsson et al. (2012). NCBI GenBank served also as the source for other DNA sequences used in this study. One or two representatives from the genera most related to Hyphodontia s.l. (Larsson et al. 2006; Larsson 2007) were selected for combined ITS+28S dataset, with Oxyporus populinus as an outgroup. Skeletocutis odora (Polyporales) was selected as the outgroup for rooting phylograms based on ITS sequences. The alignments were done with MAFFT v.7 online (Katoh and Standley 2013), using L-INS-i strategy for ITS dataset, G-INS-i for 28S, and E-INS-i for ITS sequences within the combined dataset. Both datasets were used for analysis with Bayesian inference (BI) and maximum likelihood (ML) methods. The BI phylograms were computed with MrBayes v.3.2.1 and v.3.2.6 (Ronquist and Huelsenbeck 2003), using DNA substitution models estimated by MrModeltest v.2.3 and v.2.4 (Nylander 2004). Akaike information criterion was used to select the best model for ITS+28S dataset, and Bayesian information criterion-for ITS dataset. For combined ITS +28 S dataset, the settings were ngen $=500,000$, samplefreq $=500$, nchans $=4$, and other $\mathrm{pa}$ rameters as default. For ITS dataset, the settings were ngen = $10,000,000$, samplefreq $=1000$, and other parameters as default. Partitioned analyses were applied to ITS alignments with independent nucleotide substitution models and likelihood values for ITS1, ITS2, and 5.8S. The best-fitting models for ML phylograms were calculated with MEGA7, including 1000 bootstrap (BS) replicates, the partial deletion of gapped positions with $95 \%$ site coverage cut-off, and other settings as default. MEGA7, FigTree v.1.3.1 and v.1.4.2 (Rambaut 2012) were used for processing the phylograms. The ready phylograms were prepared in CorelDRAW v.9 (Corel Corp., Ottawa, Canada, 1999). Sequence alignments and trees are deposited in TreeBASE (http://purl.org/phylo/treebase/ phylows/study/TB2:S24117).

\section{Results}

\section{Phylogeny}

The aligned combined ITS+28S datamatrix comprised of 41 taxa and 1512 positions. It was partitioned as follows: ITS1 = positions $1-473,5.8 \mathrm{~S}$ rRNA gene $=474-631$, ITS $2=632$ 986, and $28 \mathrm{~S}=987-1512$. The aligned ITS datamatrix consisted of 86 taxa and 926 positions. It was partitioned as follows: ITS1 $=$ positions $1-399,5.8 \mathrm{~S}$ rRNA gene $=400-561$, and ITS $2=562-926$. The used positions from ITS matrix amounted 453 in the ML analysis. The best models suggested by MrModeltest were GTR + I + G for ITS1, ITS2, 28S, and $\mathrm{SYM}+\mathrm{I}$ for $5.8 \mathrm{~S}$.

The high degree of accordance between BI and ML phylograms was observed for ITS+28S dataset, and moderate degree of accordance between BI and ML phylograms for ITS dataset. Bayesian topologies with integrated posterior probability (PP) values and BS values from ML analyses are presented in Figs. 1 and 2.

The phylogram based on combined ITS+28S dataset (Fig. 1) includes 31 sequences of Hyphodontia s.l. specimens and strains, of which seven were generated in this study. Sequences of the new genus, introduced herein, are clustered together in a strongly supported clade $(\mathrm{PP}=1, \mathrm{BS}=100)$. The most related genera to it are Xylodon and Lyomyces, and the all three genera are clustered in a common clade $(\mathrm{PP}=1, \mathrm{BS}=91)$.

The phylogram based on ITS dataset (Fig. 2) includes 85 sequences of Hyphodontia s.l. specimens and strains, of which 11 were generated in this study. Sequences of the new genus belong to a distinct clade ( $\mathrm{PP}=1, \mathrm{BS}=91$ ), having a significant distance to all other sequences of the genera Hastodontia, Hyphodontia s. str., Kneiffiella, Lyomyces, and Xylodon. A 


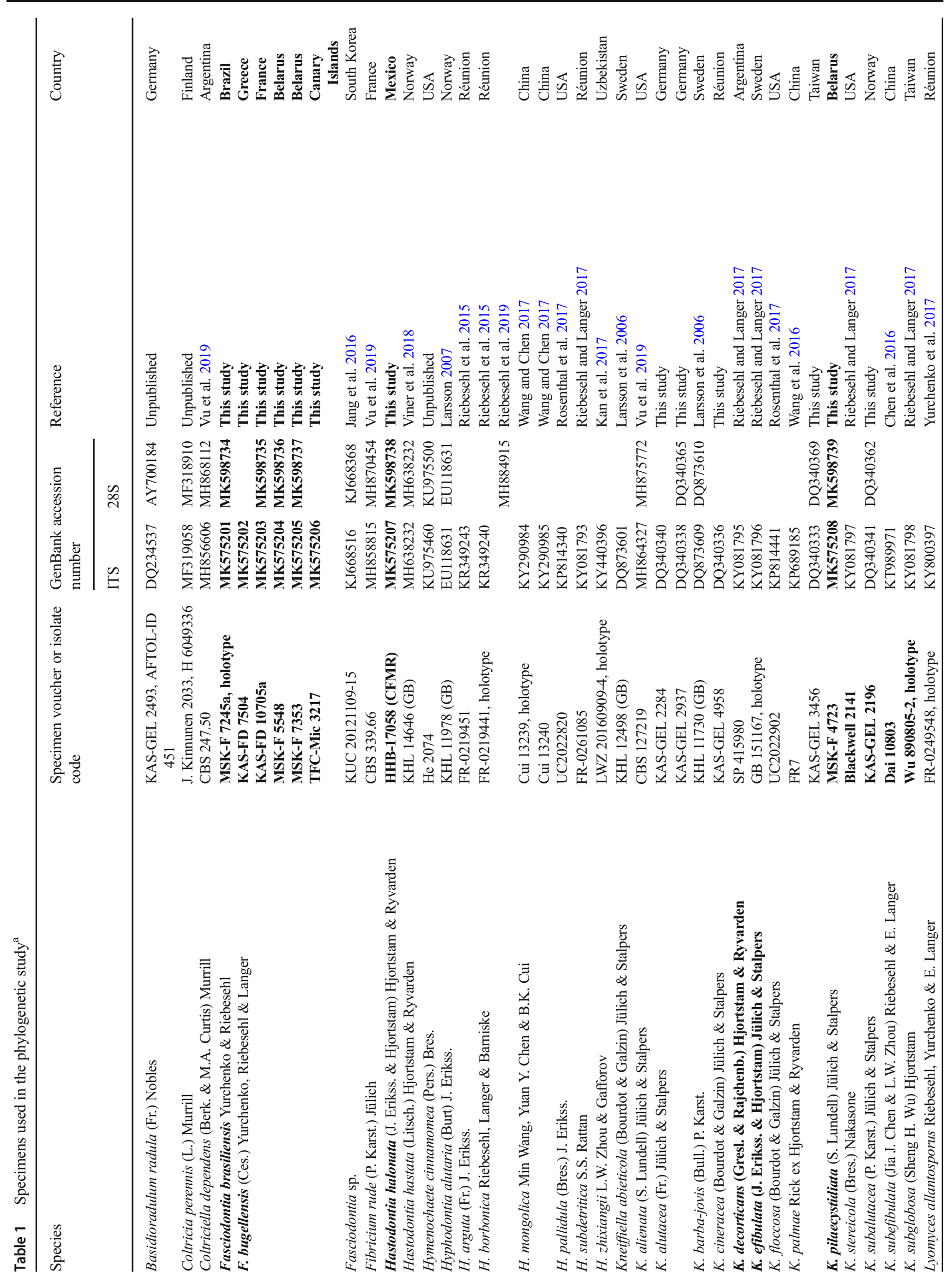




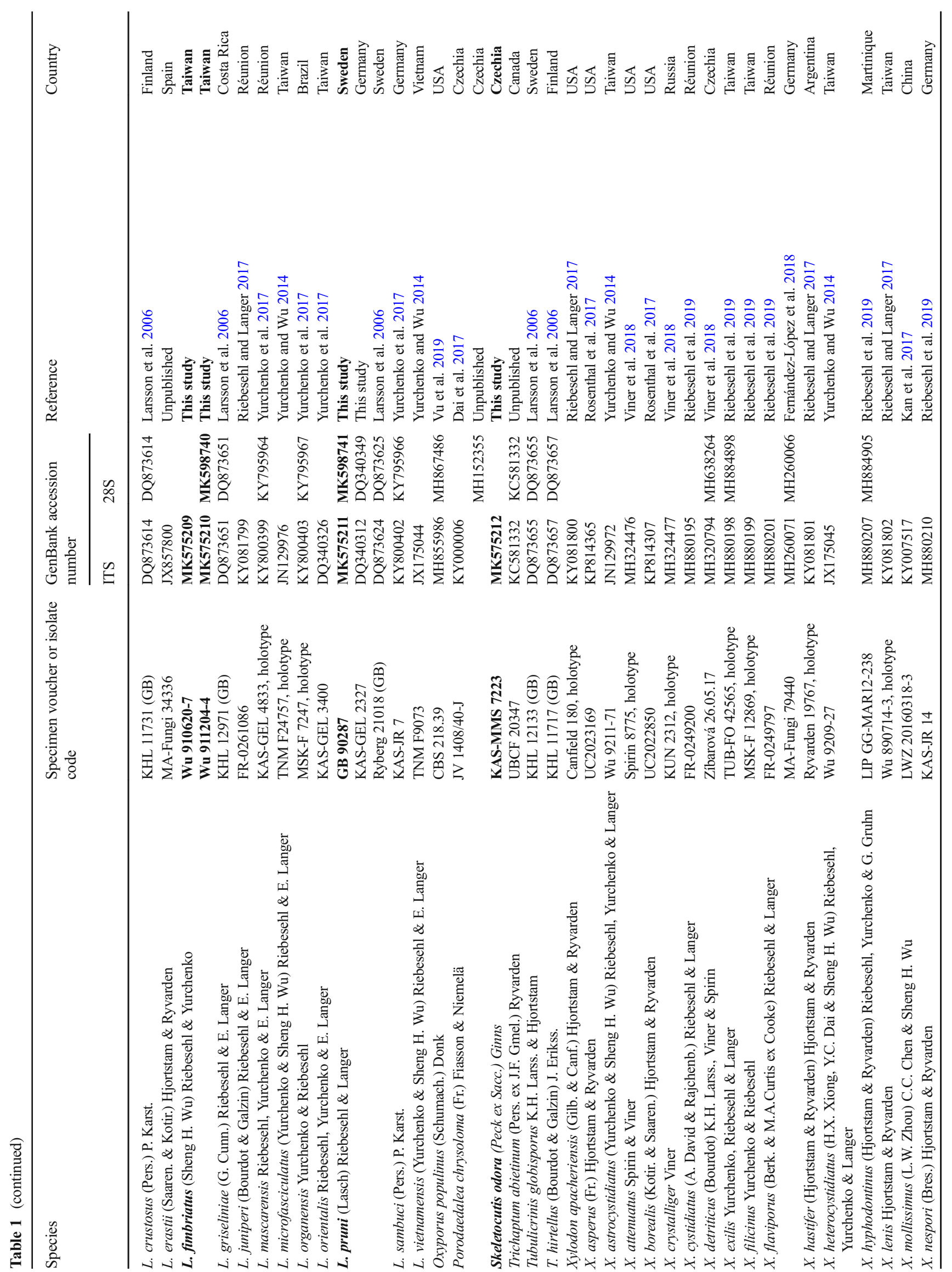




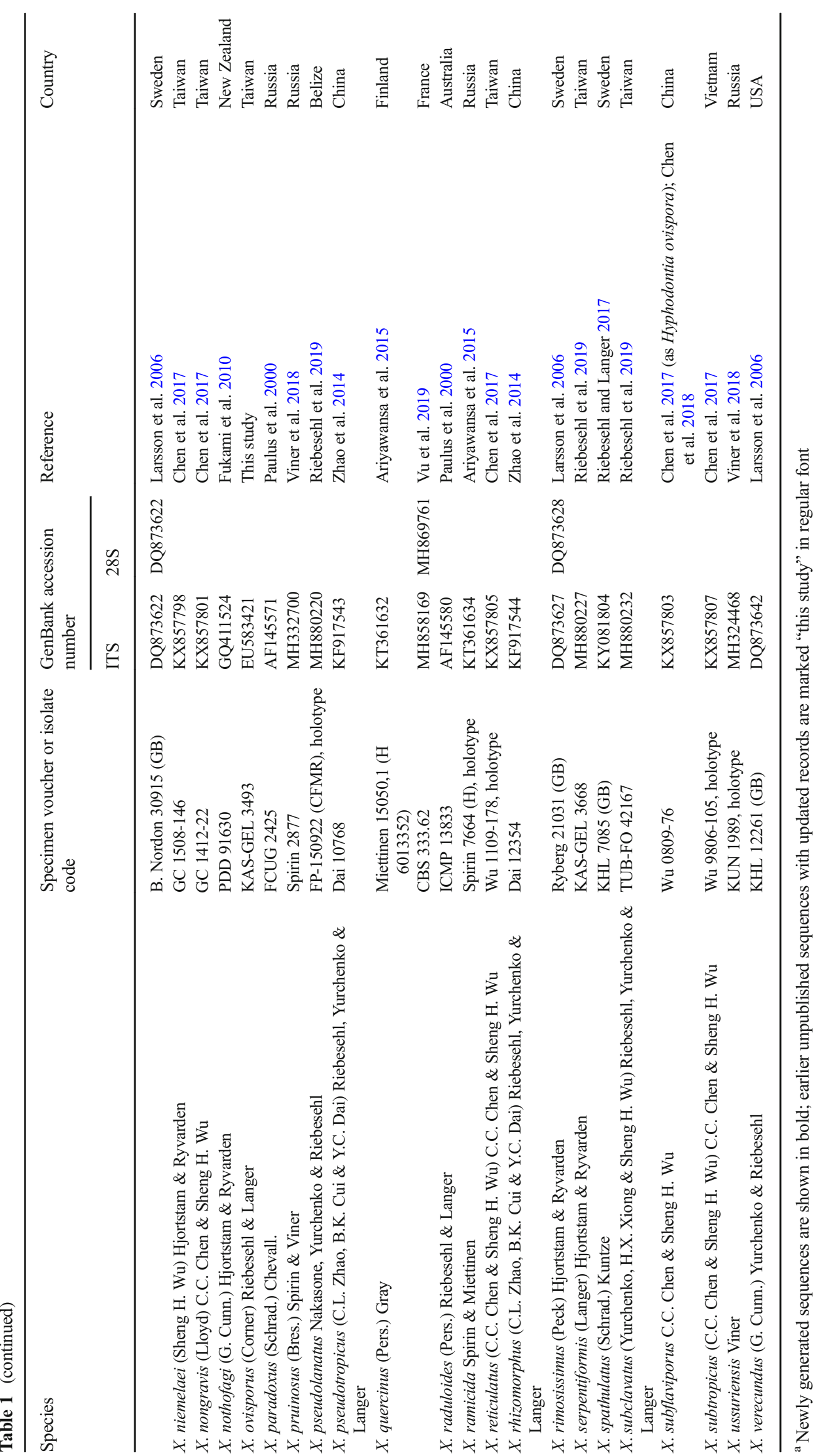


basic local alignment search tool (BLAST) search of the newly generated Fasciodontia bugellensis ITS sequences revealed that they have $94 \%$ identity to a sequence from South Korea identified as Hyphodontia sp. 2 (KUC 20121109-15). This sequence was added to our phylograms as Fasciodontia sp. (Figs. 1 and 2). The distance to sequences of F. brasiliensis and $F$. bugellensis indicates that this sequence belongs to different new Fasciodontia species, but a further study is needed with a special emphasis on the morphology of this specimen. As a result, three lineages are distinguished within the Fasciodontia clade: F. bugellensis, the newly described species F. brasiliensis, and Fasciodontia sp. from South Korea.

The phylogram based on combined dataset shows the placement of Deviodontia pilaecystidiata among species of Kneiffiella (Fig. 1). After the analysis of ITS sequences, no significant distance between Kneiffiella pilaecystidiata and Hyphodontia mongolica was observed; both taxa comprise a branch with $\mathrm{PP}=1$ and $\mathrm{BS}=99$ (Fig. 2); only 3 positions $(0.6 \%)$ are different on comparable 531 nucleotides between the ITS sequences of MSK-F 4723 (K. pilaecystidiata) and Cui 13239 (H. mongolica holotype). Two sequences of Hyphodontia mongolica show no independent cluster in ML phylogram. These data indicate that the taxa should be considered as conspecific.

The newly generated ITS and $28 \mathrm{~S}$ sequences of Hastodontia halonata demonstrate that this taxon belongs to one clade with H. hastata and Hyphodontia s. str. on ITS+28S phylogram $(\mathrm{PP}=0.99)$ and ITS phylogram $(\mathrm{PP}=0.77)$. However, no high support values were obtained to consider H. halonata and H. hastata as the members of one genus in phylogenetical sense. The position of Xylodon fimbriatus is apparently located in the genus Lyomyces (Figs. 1 and 2). ITS and 28S sequences of Kneiffiella alienata (obtained from NCBI GenBank) confirm its classification in the genus Kneiffiella (Figs. 1 and 2). Kneiffiella alienata occurred to be most phylogenetically close to $K$. cineracea and $K$. pilaecystidiata ( $\mathrm{PP}=1$, Figs. 1 and 2).

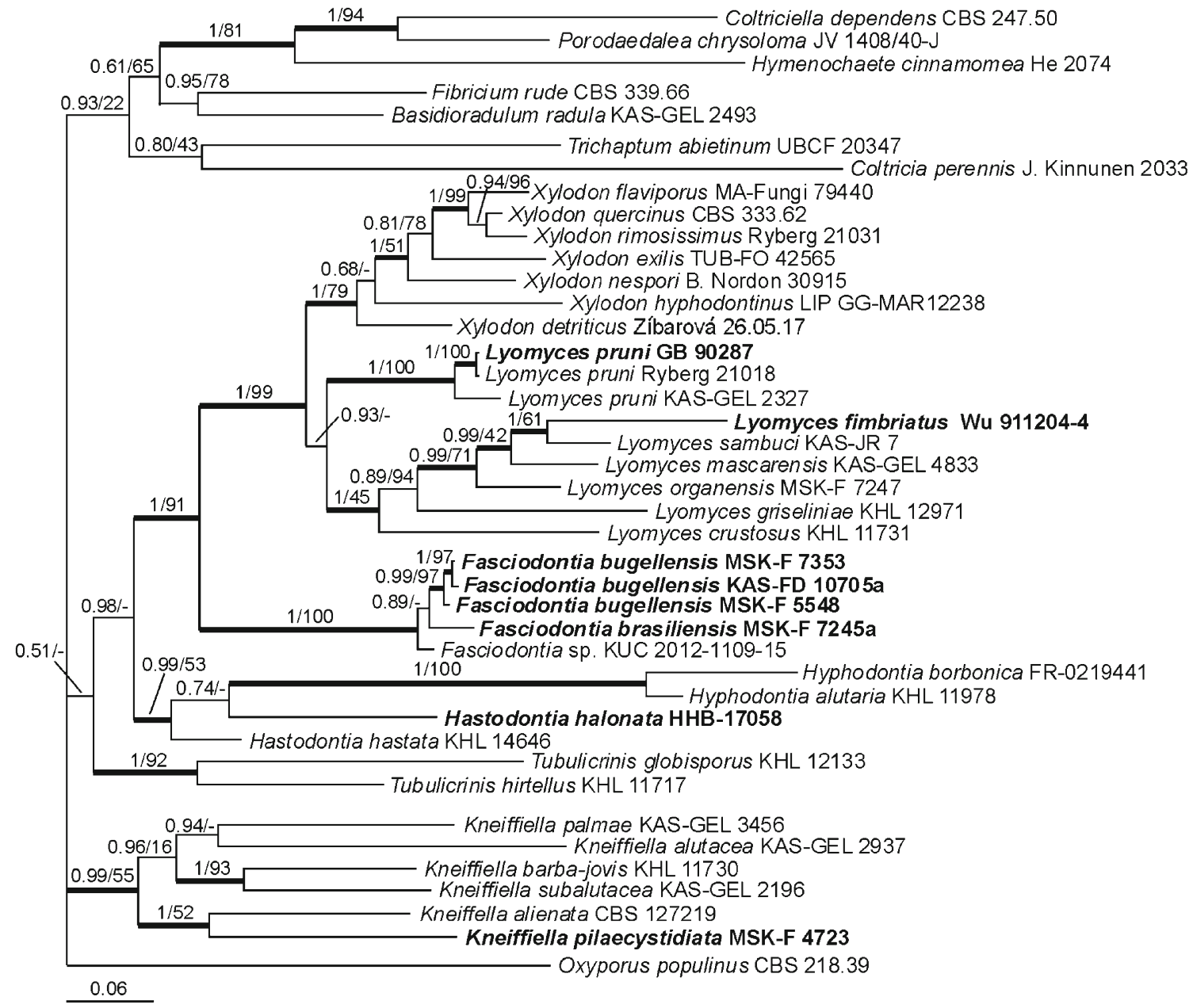

Fig. 1 Bayesian phylogram for Fasciodontia and related fungi based on combined dataset of ITS and 28S sequences. Numbers above branches indicate Bayesian posterior probability/bootstrap support (from Maximum Likelihood tree) values. Thick branches have PP $\geq 0.99$.
Scale bar: number of substitutions per nucleotide position. Names of specimens for which sequences were obtained in this study are given in bold 


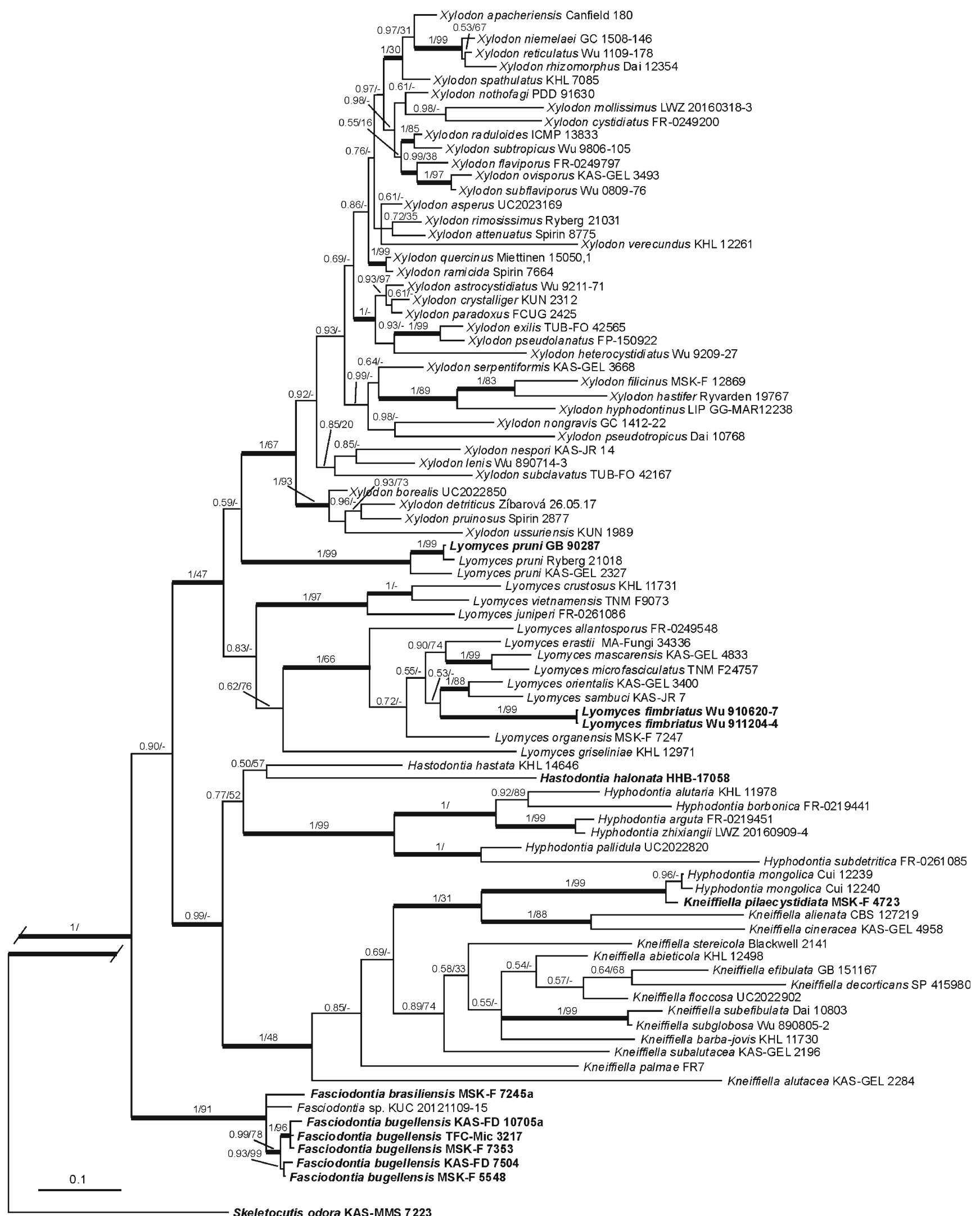

Fig. 2 Bayesian phylogram for Fasciodontia and related fungi based on ITS sequences. Conventions as for Fig. 1 


\section{Morphology}

Fasciodontia Yurchenko \& Riebesehl, gen. nov. MycoBank no.: MB829454

Type species: Fasciodontia bugellensis (Ces.) Yurchenko, Riebesehl \& Langer, comb. nov. (MB 829456). Basionym: Odontia bugellensis Ces. in Rabenhorst, Klotzschii Herb. Viv. Mycol. no. 1915, 1855. Typus: Italy, Piemonte, 'in ligno durissimo Castaneae vetustae reperi Bugellae ao 1850', leg. V. Cesati [Rabenh., Klotzschii Herb. Viv. Mycol., Cent. 20: no. 1915 (HAL, s.n.), lectotype (MycoBank no.: MBT390118), see a remark below]

Etymology. 'Fascio' (Lat.) refers to fasciculate arrangement of hyphae in aculei, 'dontia' stresses the derivative origin from Hyphodontia s.1.

Description. Basidioma effused, membranaceous, cracking with age; margin thinning out, rarely abrupt. Hymenial surface minutely odontioid, whitish or cream-colored; aculei sterile except bases and consisting of projecting hyphae. Hyphal system pseudodimitic; hyphae clamped at all primary septa, colorless in water, slightly yellowish in mass in $\mathrm{KOH}$, moderately cyanophilous, negative in Melzer's reagent; skeletal-like thick-walled hyphae present in basal subhymenium and in aculeal trama; skeletal-like hyphae in aculei loosely encrusted, apically thin-walled, partly agglutinated with age. Cystidia from cylindrical to slightly moniliform and capitate. Basidia utriform to subcylindrical, with two slight constrictions, thinwalled or slightly thick-walled in lower $1 / 2-2 / 3$, with four sterigmata. Spores ellipsoid, smooth, with thickened or thick wall (about 0.2-0.3 $\mu \mathrm{m}$ thick), colorless, negative in Melzer's reagent, slightly to moderately cyanophilous.

Distribution and ecology. The species of the genus are known from Europe, Canary Islands, Africa (Hjortstam and Ryvarden 2007a), East Asia, South America, and grow on dead wood.

Remarks. The main diagnostic features of the genus are minutely odontioid hymenophore, presence of thick-walled skeletal-like hyphae, associated with aculeal trama, submoniliform cystidia, which are from seldom to numerous, confined mostly to the base of aculei, and thick-walled basidiospores. Xylodon is the closest genus to Fasciodontia in both morphological and molecular aspects. However, the species of Xylodon with thickwalled spores $[X$. brevisetus, $X$. capitatus (G. Cunn.) Hjortstam \& Ryvarden, $X$. detriticus, X. rickii (Hjortstam \& Ryvarden) Riebesehl \& Langer, and X. septocystidiatus (H.X. Xiong, Y.C. Dai \& Sheng H. Wu) Riebesehl \& Langer] lacked the combination of characters listed above. Xylodon crassisporus (Greslebin \& Rajchenberg) Hjortstam \& Ryvarden has spores, basidia, cystidia, and pseudoskeletal hyphae in teeth similar with Fasciodontia. However, this species possesses capitate cystidia with yellowish resinous caps (Greslebin and Rajchenberg 2000). Hyphodontia sinensis H.X. Xiong, Y.C. Dai \& Sheng H. Wu has hyphae, structure of aculeal trama, and basidiospores somewhat similar with Fasciodontia. In the same time, H. sinensis has longcylindrical, thin-walled embedded cystidia (Xiong et al. 2010), which are not peculiar to Fasciodontia. The exact taxonomic position of $X$. crassisporus and $H$. sinensis will be stated only after their DNA sequences will be available.

Publication of the new species Odontia bugellensis was based on exsiccata "Herbarium Vivum Mycologicum" distributed and stored in several herbaria, with no indication of a solitary holotype. In this study, we have selected and designated as lectotype an exsiccatum stored in HAL (see Braun 2018). Microscopic examination of this material showed the main diagnostic features of F. bugellensis: cracking odontioid basidioma, constricted cystidia, and thick-walled spores; $\mathrm{L}=6.07 \mu \mathrm{m}, \mathrm{W}=4.12 \mu \mathrm{m}$, and $\mathrm{Q}=1.48$.

Fasciodontia brasiliensis Yurchenko \& Riebesehl, sp. nov. Figs. 3 and 4.

MycoBank no.: MB829457

Etymology. 'Brasiliensis' refers to Brazil, the country where this species was found.

Holotype. Brazil, Rio de Janeiro State, Serra dos Órgãos Mt. Range, E slopes of Mt. Pico do Tinguá, Tinguá village vicinity, $22^{\circ} 36.5^{\prime} \mathrm{S}, 43^{\circ} 27.5^{\prime} \mathrm{W}$, ca $1000 \mathrm{~m}$ asl., tropical rainforest, on fallen angiosperm branch, leg. E. Yurchenko, 23 Aug 2009 (MSK-F 7245a; isotypes in CFMR and KAS).

Description. Basidioma effused, ca $0.5-5 \mathrm{~cm}$ long, creamcolored, odontioid with conical aculei 50-125 $\mu \mathrm{m}$ long and 20$60 \mu \mathrm{m}$ in diameter at base, $7-10$ aculei $/ \mathrm{mm}$; the part between aculei loose, minutely porulose, 40-70 $\mu \mathrm{m}$ thick. Margin diffuse or felty and then about $0.25 \mathrm{~mm}$ wide. Hyphal system pseudodimitic, hyphae colorless, smooth or poorly encrusted, clamped at all primary septa. Subicular hyphae moderately branched, 2-3 $\mu \mathrm{m}$ wide, thin- to thick-walled (walls up to $0.8 \mu \mathrm{m}$ thick), smooth, with rare simple (secondary) septa. Subhymenial hyphae moderately to richly branched, 1.5-3 $\mu \mathrm{m}$ wide, thin-walled. Aculei sterile, consisting of densely arranged, parallel projecting hyphae, originating in subiculum. Projecting hyphae flexuous, 45-75 $\times 2.5-3.5 \mu \mathrm{m}$, from thin- to usually thick-walled (walls ca $1 \mu \mathrm{m}$ thick in lower 2/3) and then skeletal-like, with simple septa and slight constrictions, loosely encrusted by crystals 2-3 $\mu \mathrm{m}$ across, apically blunt, subacute, seldom subcapitate. Hymenial elements thin-walled. Cystidia arranged mostly at bases of aculei, subcylindrical, clavate or capitate, sometimes slightly moniliform, smooth or barely encrusted, 15-25(45) $\times 3-5 \mu \mathrm{m}$. Elements of intermediate morphology between cystidia and basidioles present. Basidioles clavate to utriform, smooth or slightly encrusted, 10-20 × 3.5-4.5 $\mu \mathrm{m}$. Basidia utriform with 2 constrictions, 19-21 $\times 4-5 \mu \mathrm{m}$, with four sterigmata 4.5-5 $\times 0.5-0.7 \mu \mathrm{m}$. Basidiospores ellipsoid, 4.5$5(5.5) \times 3-3.5(3.8) \mu \mathrm{m}$ (for holotype $\mathrm{L}=4.89 \mu \mathrm{m}, \mathrm{W}=$ $3.41 \mu \mathrm{m}, \mathrm{Q}=1.44$ ), smooth, slightly thick-walled, negative in Melzer's reagent, slightly cyanophilous, with short and blunt apiculus, contents often somewhat granular and with a large central drop (Table 1). 
Fig. 3 Hymenial surface view of Fasciodontia bugellensis (KASFD 10705a, left) and

F. brasiliensis (MSK-F 7245a, holotype, right ). Scale bars $=$ $1 \mathrm{~mm}$

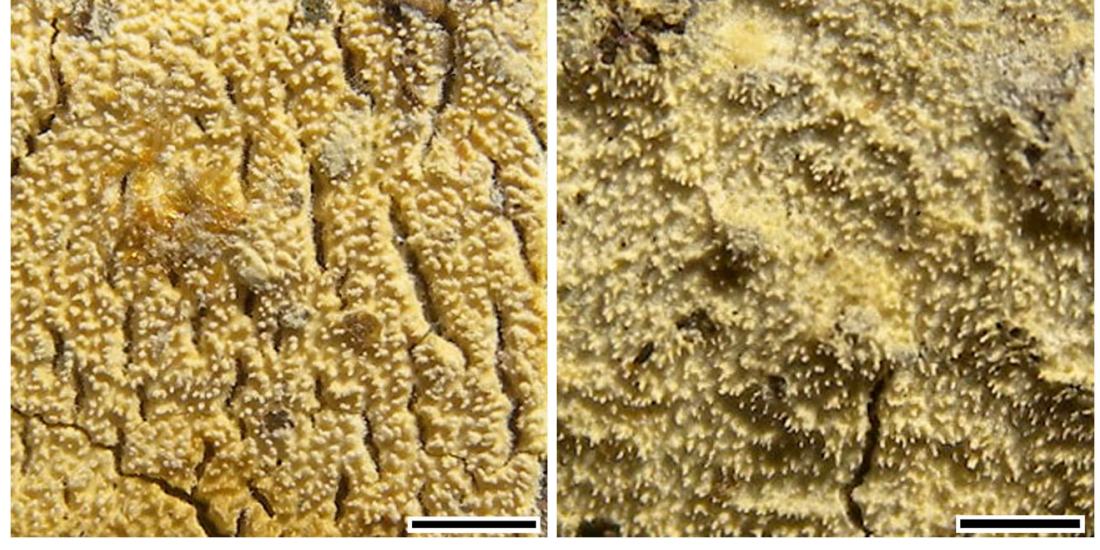

Fig. 4 Micromorphology of Fasciodontia brasiliensis (MSKF 7245a, holotype): a Vertical section of basidioma. b Subicular hyphae. $\mathbf{c}$ Hyphae at base of aculeal trama. d Projecting hyphae in aculeus. e Separate projecting hyphae. f Encrusted apices of projecting hyphae. $\mathbf{g}$ Cystidia at base of aculeus. $\mathbf{h}$ Portion of hymenium and subhymenium. i Cystidia. j Basidia. k Basidiospores. Scale bars: $\mathbf{a}=20 \mu \mathrm{m} ; \mathbf{b}-\mathbf{j}=10 ; \mathbf{k}=$ $5 \mu \mathrm{m}$

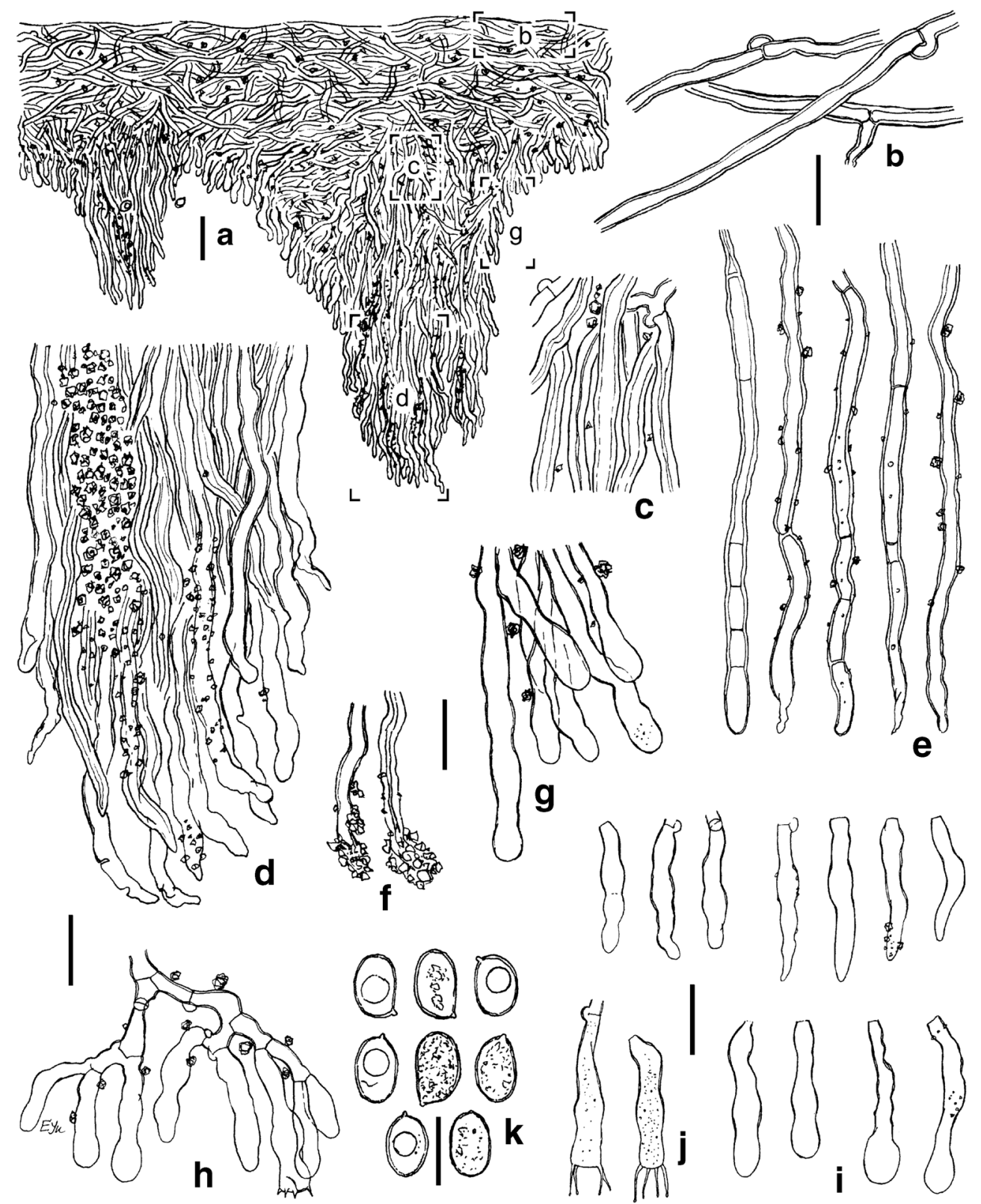


Table 2 Morphological differences between Fasciodontia species

F. bugellensis

Basidioma consistency

Crystals in subiculum and subhymenium

Subhymenium thickness, $\mu \mathrm{m}$

Subhymenium texture

Skeletal-like hyphae arrangement

Submoniliform cystidia occurrence

Walls of cystidia

Basidia size, $\mu \mathrm{m}$

Basidiospores size, $\mu \mathrm{m}$
Membranaceous to almost cretaceous

Usually abundant

$100-250$

Dense due to agglutinated hyphae

Present mostly in basal subhymenium and aculei

Scattered to common

Often slightly thick-walled towards the base

(18) $22-30 \times 4-4.5$

$5.3-6.3 \times 3.7-4(4.5)$
F. brasiliensis

Membranaceous

In most parts unabundant or poor

$15-40$

Slightly open (in thin vertical sections)

Often penetrate the whole volume of

basidioma from subiculum to aculeal apices Scattered or rare

Mostly thin-walled or almost so

$19-21 \times 4-5$

$4.5-5(5.5) \times 3-3.5(3.8)$
Fig. 5 Micromorphology of Fasciodontia bugellensis. KASFD 10705a: a Vertical section of basidioma. b Subicular hyphae. c Hyphae in basal subhymenium. d Separate skeletal-like hyphae from basal subhymenium. e Hyphae in middle subhymenium. f, $\mathbf{g}$ Projecting hyphae in aculei. $\mathbf{h}$ Cystidia. i Basidioles. j Basidia. k Basidiospores. MSK-F 7353: m Subcapitate cystidia. Scale bars: $\mathbf{a}=100 \mu \mathrm{m} ; \mathbf{b}-\mathbf{j}, \mathbf{m}=10 \mu \mathrm{m} ; \mathbf{k}=$ $5 \mu \mathrm{m}$
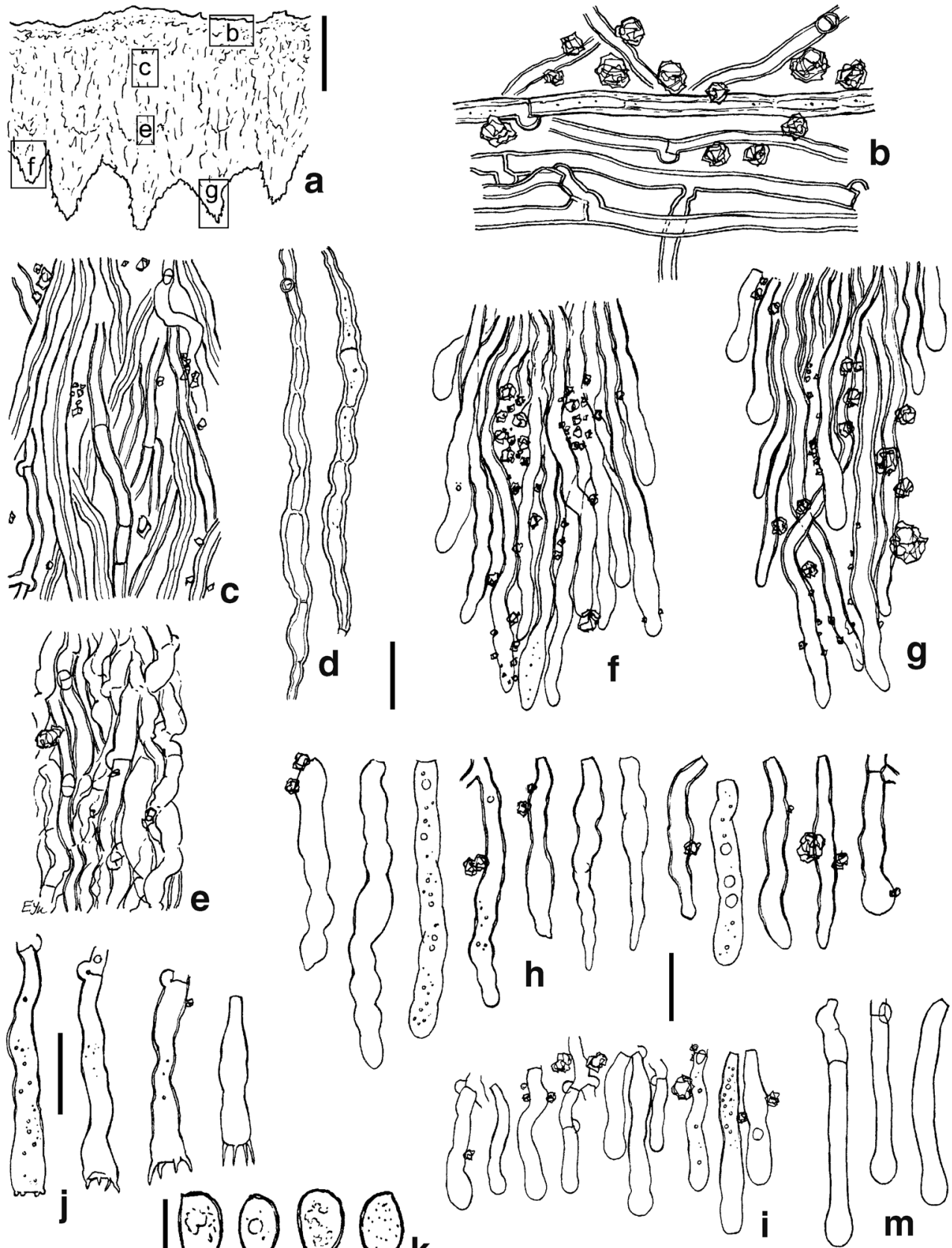

$\mathrm{m}$ 
Fig. 6 Micromorphology of Lyomyces pruni (GB 90287). a Vertical section of basidioma. $\mathbf{b}$ Subicular hyphae near substratum. c Subicular (medullary) and subhymenial hyphae. d Aculeal apex. e Capitate cystidia. f Cylindrical cystidia. $\mathbf{g}$ Subulate cystidium. h Basidioles. i Basidia. j Basidiospores. Scale bars: $\mathbf{a}=100 \mu \mathrm{m} ; \mathbf{b}-\mathbf{i}=10 \mu \mathrm{m}$; $\mathbf{j}=5 \mu$
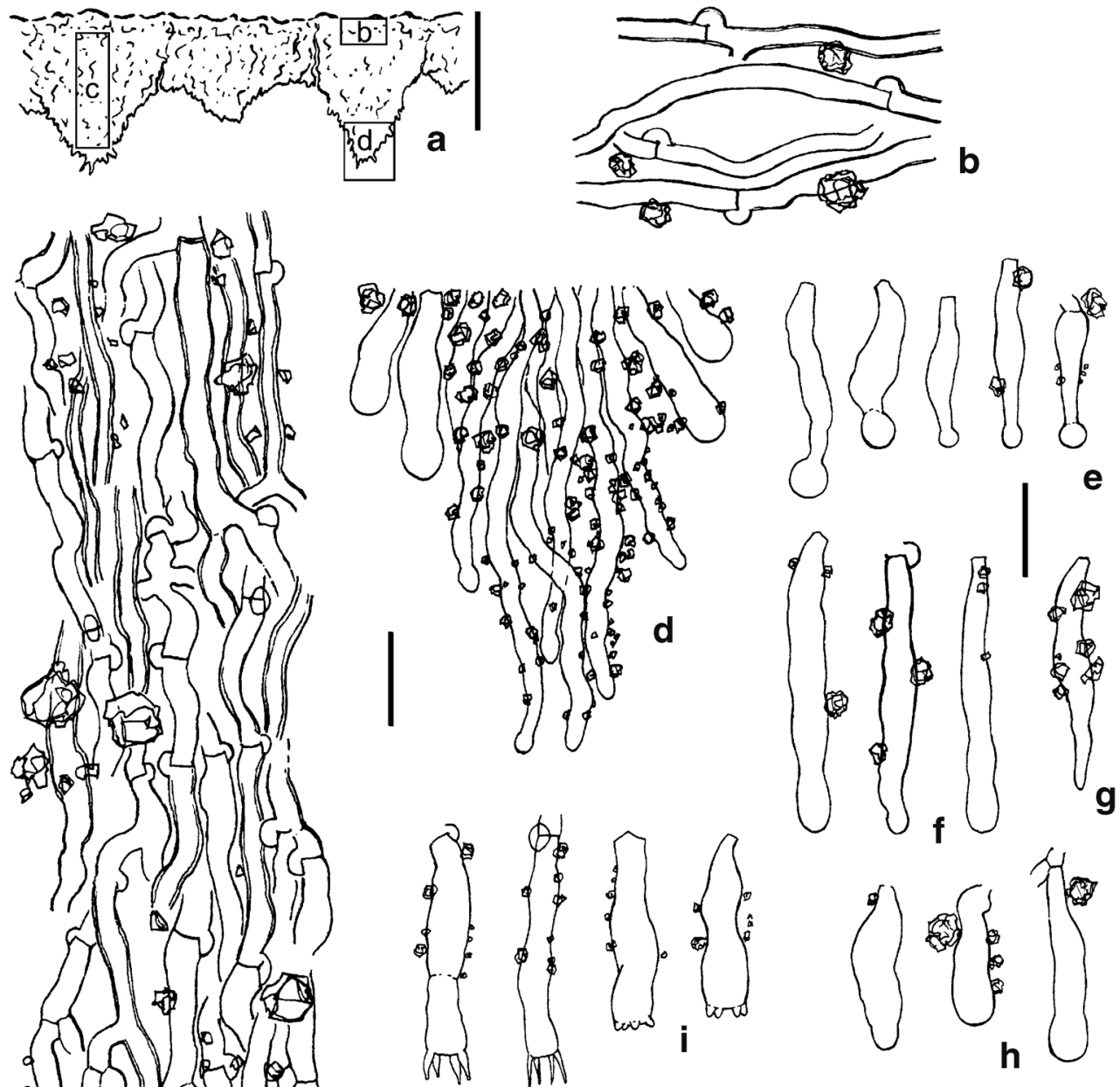

9

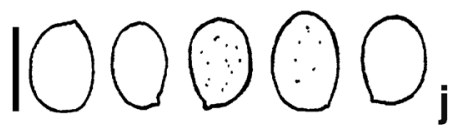

preference of $H$. pilaecystidiata to Salicaceae. The specimen of H. pilaecystidiata from Belarus was compared by us with a specimen from Sweden, identified by J. Eriksson under the same name, and we found that their morphology was identical. The description of H. mongolica shows larger cystidia and shorter basidia than we have seen in specimens from Belarus and Sweden. However, taking into account ITS sequence and ITS phylogeny data (see above), H. mongolica should be synonymized with Kneiffiella pilaecystidiata. Consequently, the genus Deviodontia, proposed with a single species D. pilaecystidiata (Hjortstam and Ryvarden 2009), is a synonym of Kneiffiella. For description and illustration of K. pilaecystidiata, we refer to Yurchenko and Kotiranta (2007). The description of $H$. pilaecystidiata by Eriksson and Ryvarden (1976) notes thin-walled hyphae in basidioma; the picture from the same source shows heterogeneous contents of cystidia. However, our data, together with the data of Wang and Chen (2017), demonstrated thin- to thick-walled hyphae and homogeneous contents of cystidia.

Specimens examined. Belarus: Lepel' distr., Byarezinski Biosphere Reserve, near Domzharytsy village, on dead, erect trunk tum of Chinese collections (Populus) is also in agreement with the 
Table 3 Morphological differences between Fasciodontia bugellensis and Lyomyces pruni

\begin{tabular}{lll}
\hline & F. bugellensis & L. pruni \\
\hline Basidioma consistency & Hard-membranaceous to almost cretaceous & Soft-membranaceous, fragile in dry state \\
Basidioma thickness between aculei, $\mu \mathrm{m}$ & $75-400$ & $40-200$ \\
Aculei height $\times$ width (at base), $\mu \mathrm{m}$ & $40-125 \times 40-100$ & $25-90 \times 25-75$ \\
Aculei fertility & Lacked fertile hymenium or with & Fertile except the apical part \\
Walls of subicular hyphae & Thickened to thick & Thin \\
Skeletal-like hyphae & Present & Absent \\
Constricted cystidia & Present & Absent \\
Bowl-pin-shaped cystidia & Absent & Present \\
Cystidial elements and basidia walls & Often slightly thick-walled in lower 2/3 & Thin-walled \\
Shape of the ends of projecting hyphae at aculeal tips & Obtuse or tapering & Obtuse or capitulate \\
Basidioles shape & Subcylindrical & Mostly clavate \\
Basidia width, $\mu \mathrm{m}$ & $4-4.5$ & $4.5-5$ \\
Basidia contents & More or less guttulate & Homogeneous \\
Spore wall & More or less thick-walled & Thin-walled \\
\hline
\end{tabular}

of Salixpentandra L., leg. E. Yurchenko, 2 Jun 1999 (MSK-F 4723); Sweden: Norrbotten, Nedertorneå Co., Säivisnäs, on decayed wood of cf. Salix, leg. J. Eriksson, 25 Aug 1960 (GB 94365).

\section{Lyomyces fimbriatus (Sheng H. Wu) Riebesehl \& Yurchenko, comb. nov.}

MycoBank no.: MB830811

Basionym: Hyphodontia fimbriata Sheng H. Wu, Acta Botanica Fennica 142: 90 (1990)

Syn.: Xylodon fimbriatus (Sheng H. Wu) Hjortstam \& Ryvarden, Synopsis Fungorum 26: 43 (2009), nom. illeg.

Typus: Taiwan, Nantou, Yushan National Park, 2200 m asl., on fallen twig of angiosperm, leg. S.H. Wu, 29 Jul 1988 (Wu 880729-13, holotype in H, isotype in TNM)

In respect to morphology, L. fimbriatus has white or whitish basidiomata, loose hyphal texture, rich crystalline material in subhymenium and subiculum, thin-walled capitate cystidia, and guttulate basidiospores (Wu 1990; Langer 1994), like the taxa of Lyomyces sambuci complex.

The name Xylodon fimbriatus (Sheng $\mathrm{H}$. Wu) Hjortstam \& Ryvarden must be considered as illegitimate according to Art. 53.1 (Turland et al. 2018) because of existence of the name $X$. fimbriatus (Pers.) Chevall., published in 1826, and today belonged to synonyms of Steccherinum fimbriatum (Pers.) J. Erikss. (Species Fungorum 2019).

\section{Discussion}

\section{Fasciodontia bugellensis and Lyomyces pruni}

Our morphology and molecular phylogeny studies showed clear differences between Fasciodontia bugellensis (Figs. 3 and 5) and Lyomyces pruni (Fig. 6). Earlier Hyphodontia bugellensis and $H$. pruni were treated as conspecific by the authors of "The Corticiaceae of North Europe" (Eriksson and Ryvarden 1976). They grounded this conclusion on the analysis of type material, stored in S herbarium, done by Kurt Hjortstam. Later, Hjortstam (1991) reintroduced the name $H$. bugellensis. In subsequent works, H. bugellensis (combined also as Xylodon bugellensis) was treated as an independent species (Melo and Tellería 1997; Hjortstam and Ryvarden 2007a, b; Bernicchia and Gorjón 2010; Martini 2016). The main distinctive feature for $X$. bugellensis was described as spores "distinctly thick-walled" (Hjortstam 1991; Bernicchia and Gorjón 2010) or "when mature with a slight wall thickening" (Hjortstam and Ryvarden 2007b). In the same time, $H$. pruni and $H$. bugellensis were treated as conspecific by Langer (1994). The differences between these species are described in Table 3.

Along with these features, spore and crystalline material size and shape are identical in both species. Besides, both taxa have cylindrical cystidia and the tendency to form aculei in parallel rows. The descriptions of Hyphodontia bugellensis were published by Melo and Tellería (1997), Bernicchia and Gorjón (2010), and Martini (2016). In the description of H. bugellensis specimens from Venezuela (Hjortstam and Ryvarden 2007b), the authors note tibiiform and lecythiform cystidia which we did not observe in the European material.

We emend the species concept of Fasciodontia bugellensis by thick-walled, skeletal-like hyphae, confined to the aculei and situated also beneath them. Such hyphae, or hyphal segments, are observed in the core of aculei and partly on the border between subiculum and subhymenium, whereas in middle subhymenium they are evidently masked by hyphae with thinner walls, or absent. 
Specimens examined. Fasciodontia bugellensis-Belarus: Mar'ina Horka town vicinity, on dead attached branches of Malus sp., leg. E. Yurchenko, 15 Nov 1992 (MSK-F 5548); Zhytkavichy distr., Khlupinskaya Buda, on branch of dead erect Malus sylvestris Mill., leg. E. Yurchenko, 20 May 2010 (MSK-F 7353); France: Îles d'Hyères, Porquerolles, on fallen branch of Pinus halepensis Mill., leg. F. Dämmrich, 13 Nov 2013 (KAS-FD 10705a, dup. in private herbarium of Frank Dämmrich); Greece: Rhodos, on deciduous wood, leg. F. Dämmrich, 20 Oct 2004 (KAS-FD 7504, dup. in private herbarium of Frank Dämmrich); Spain: Canary Islands, El Hierro, Fayal-Brezal forest, on dead wood of Myrica faya Ait., leg. E. Beltrán, L. Rodríguez, 10 Sep 1988 (TFC-Mic 3217, dup. in KAS); Canary Islands, La Gomera, on dead wood, leg. L. Ryvarden, 16 Jan 1974 (KAS-LR 12558). Lyomyces pruni-Sweden: Västergötland, Medelplana, Råbäck, on decayed trunk of Ulmus sp., leg. K. Hjortstam, 9 Oct 1970 (GB-Hjm 5257; dup. in KAS and MSK); ibid., on wood of cf. Corylus, leg. K. Hjortstam, 17 Oct 2007 (GB 90287; dup. in KAS and MSK).

Acknowledgments The authors are grateful to Uwe Braun, the curator of herbarium in the Institute of Biology, Martin-Luther-Universität HalleWittenberg (HAL), for the help in lectotypification of Fasciodontia bugellensis. We are thankful to Ellen Larsson, the curator of fungal collection at the University of Göteborg (GB), for providing the specimens of Lyomyces pruni and Kneiffiella pilaecystidiata for our studies; to Karen K. Nakasone and Beatriz Ortiz-Santana (Center of Forest Mycology Research, Madison, USA) for giving us the specimens of Hastodontia halonata, and Lyomyces fimbriatus from CFMR collection; to Manuel Striegel (University of Regensburg, Germany) and Frank Dämmrich (Limbach-Oberfrohna, Germany) for the additional specimens of Fasciodontia bugellensis. Significant technical support for this study was provided by Ulrike Frieling and Sylvia Heinemann (University of Kassel, Germany). The three anonymous reviewers are acknowledged for the critical considerations of the manuscript.

\section{Compliance with ethical standards}

Conflict of interest The authors declare that they have no conflict of interest.

\section{References}

Ariyawansa HA, Hyde KD, Jayasiri SC et al (2015) Fungal diversity notes 111-252-taxonomic and phylogenetic contributions to fungal taxa. Fungal Divers 7:27-274. https://doi.org/10.1007/s13225-0150346-5

Benson DA, Cavanaugh M, Clark K, Karsch-Mizrachi I, Ostell J, Pruitt KD, Sayers EW (2018) GenBank. Nucleic Acids Res 46(D1):D41D47. https://doi.org/10.1093/nar/gkx1094

Bernicchia A, Gorjón SP (2010) Corticiaceae s. 1. (Fungi Europaei). Edizioni Candusso

Braun U (2018) Annotated list of taxonomic novelties published in "Herbarium Vivum Mycologicum" issued by J. F. Klotzsch and G. L. Rabenhorst between 1832 and 1855. Schlechtendalia 34:3-90

Bunyard BA, Chaichuchote S, Nicholson MS, Royse DJ (1996) Ribosomal DNA analysis for resolution of genotypic classes of
Pleurotus. Mycol Res 100:143-150. https://doi.org/10.1016/ S0953-7562(96)80112-2

Chen JJ, Zhou LW, Ji XH, Zhao CL (2016) Hyphodontia dimitica and H. subefibulata spp. nov. (Schizoporaceae, Hymenochaetales) from southern China based on morphological and molecular characters. Phytotaxa 269:1-13. https://doi.org/10.11646/phytotaxa.269.1.1

Chen CC, Wu SH, Chen CY (2017) Three new species of Hyphodontia s.l. (Basidiomycota) with poroid or raduloid hymenophore. Mycol Prog 16:553-564. https://doi.org/10.1007/s11557-017-1286-0

Chen CC, Wu SH, Chen CY (2018) Xylodon subflaviporus sp. nov. (Hymenochaetales, Basidiomycota) from East Asia. Mycoscience 59:343-352. https://doi.org/10.1016/j.myc.2017.12.004

Collopy PD, Largeteau-Mamoun ML, Romaine CP, Royse DJ (2001) Molecular phylogenetic analyses of Verticillium fungicola and related species causing dry bubble disease of the cultivated button mushroom, Agaricus bisporus. Phytopathology 91:905-912. https://doi. org/10.1094/PHYTO.2001.91.9.905

Dai SJ, Vlasák J, Tomšovský M, Wu F (2017) Porodaedalea chinensis (Hymenochaetaceae, Basidiomycota)-a new polypore from China. Mycosphere 8:986-993. https://doi.org/10.5943/mycosphere/8/6/2

Eriksson J (1958) Studies in the Heterobasidiomycetes and Homobasidiomycetes - Aphyllophorales of Muddus National Park in North Sweden. Symb Bot Upsal 16:1-172

Eriksson J, Ryvarden L (1976) The Corticiaceae of North Europe, Vol. 4: Hyphodermella - Mycoacia. Fungiflora, Oslo

Fernández-López J, Martín MP, Dueñas M, Telleria MT (2018) Multilocus phylogeny reveals taxonomic misidentification of the Schizopora paradoxa (KUC8140) representative genome. MycoKeys 38:121127. https://doi.org/10.3897/mycokeys.38.28497

Fukami T, Dickie IA, Wilkie PJ, Paulus BC, Park D, Roberts A, Buchanan PK, Allen RB (2010) Assembly history dictates ecosystem functioning: evidence from wood decomposer communities. Ecol Lett 13:675-684. https://doi.org/10.1094/PHYTO.2001.91.9. 905

Gardes M, Bruns TD (1993) ITS primers with enhanced specificity for basidiomycetes-application to the identification of mycorrhizae and rusts. Mol Ecol 2:113-118. https://doi.org/10.1111/j.1365-294X. 1993.tb00005.x

Greslebin AG, Rajchenberg M (2000) The genus Hyphodontia in the Patagonian Andes forests of Argentina. Mycologia 92:1155-1165. https://doi.org/10.2307/3761483

Hjortstam K (1991) Athelopsis instead of Pteridomyces (Corticiaceae, Basidiomycetes). Mycotaxon 42:149-154

Hjortstam K, Ryvarden L (2002) Studies in tropical corticioid fungi (Basidiomycota, Aphyllophorales): Alutaceodontia, Botryodontia, Hyphodontia s.s. and Kneiffiella. Synopsis Fungorum 15:7-17

Hjortstam K, Ryvarden L (2007a) Checklist of corticioid fungi (Basidiomycotina) from the tropics, subtropics, and the southern hemisphere. Synopsis Fungorum 22:27-146

Hjortstam K, Ryvarden L (2007b) Studies in corticioid fungi from Venezuela III (Basidiomycotina, Aphyllophorales). Synopsis Fungorum 23:56-107

Hjortstam K, Ryvarden L (2009) A checklist of names in Hyphodontia sensu stricto-sensu lato and Schizopora with new combinations in Lagarobasidium, Lyomyces, Kneiffiella, Schizopora, and Xylodon. Synopsis Fungorum 26:33-55

Jang Y, Jang S, Lee J, Lee H, Lim YW, Kim C, Kim JJ (2016) Diversity of wood-inhabiting polyporoid and corticioid fungi in Odaesan National Park, Korea. Mycobiology 44:217-236. https://doi.org/ 10.5941/MYCO.2016.44.4.217

Kan YH, Qin WM, Zhou LW (2017) Hyphodontia mollissima sp. nov. (Schizoporaceae, Hymenochaetales) from Hainan, southern China. Mycoscience 58:297-301. https://doi.org/10.1016/j.myc.2017.04. 003 
Katoh K, Standley DM (2013) MAFFT multiple sequence alignment software version 7: improvements in performance and usability. Mol Biol Evol 30:772-780. https://doi.org/10.1093/molbev/mst010

Kumar S, Stecher G, Tamura K (2016) MEGA7: molecular evolutionary genetics analysis version 7.0 for bigger datasets. Mol Biol Evol 33: 1870-1874. https://doi.org/10.1093/molbev/msw054

Langer E (1994) Die Gattung Hyphodontia John Eriksson. Bibl Mycol 154:1-298

Larsson KH (2007) Re-thinking the classification of corticioid fungi. Mycol Res 111:1040-1063. https://doi.org/10.1016/j.mycres.2007. 08.001

Larsson KH, Parmasto E, Fischer M, Langer E, Nakasone KK, Redhead SA (2006) Hymenochaetales: a molecular phylogeny for the hymenochaetoid clade. Mycologia 98:926-936. https://doi.org/10. 3852/mycologia.98.6.926

Martini E (2016) Xylodon bugellensis. Crusts and gells: Descriptions and reports of resupinate Aphyllophorales and Heterobasidiomycetes Issue № 7, 27 Apr 2016. http://www.aphyllo.net

Melo I, Tellería MT (1997) Hyphodontia bugellensis (Basidiomycetes, Corticiaceae) in the Iberian Peninsula. Portugaliae Acta Biologica, Série B, Sistemática, ecologia, biogeografia e paleontologia 17:105109

Nilsson RH, Tedersoo L, Abarenkov K, Ryberg M, Kristiansson E, Hartmann M, Schoch CL, Nylander JAA, Bergsten J, Porter TM, Jumpponen A, Vaishampayan P, Ovaskainen O, Hallenberg N, Bengtsson-Palme J, Eriksson KM, Larsson KH, Larsson E, Kõljalg U (2012) Five simple guidelines for establishing basic authenticity and reliability of newly generated fungal ITS sequences. MycoKeys 4:37-63. https://doi.org/10.3897/mycokeys.4.3606

Nylander JAA (2004) MrModeltest v2. Program distributed by the author. Evolutionary Biology Centre, Uppsala University. https:// github.com/nylander/MrModeltest2

O’Donnell K (1993) Fusarium and its near relatives. In: Reynolds DR, Taylor JW (eds) Fungal systematics; the fungal holomorph: mitotic, meiotic and pleomorphic speciation. CAB International, Wallingford, pp 223-225

Paulus B, Hallenberg N, Buchanan PK, Chambers GK (2000) A phylogenetic study of the genus Schizopora (Basidiomycota) based on ITS DNA sequences. Mycol Res 104:1155-1163. https://doi.org/ $10.1017 /$ S0953756200002720

Rambaut A (2012) FigTree v1.4http://tree.bio.ed.ac.uk/software/figtree. Accessed 5 December 2012

Riebesehl J, Langer E (2017) Hyphodontia s.l. (Hymenochaetales, Basidiomycota): 35 new combinations and new keys to all 120 current species. Mycol Prog 16:637-666. https://doi.org/10.1007/ s11557-017-1299-8

Riebesehl J, Langer EJ, Ordynets A, Striegel MM, Witzany C (2015) Hyphodontia borbonica, a new species from La Réunion. Mycol Prog 14:104. https://doi.org/10.1007/s11557-015-1126-Z

Riebesehl J, Yurchenko E, Nakasone KK, Langer E (2019) Phylogenetic and morphological studies in Xylodon (Hymenochaetales, Basidiomycota) with the addition of four new species. MycoKeys 47:97-137. https://doi.org/10.3897/mycokeys.47.31130

Ronquist F, Huelsenbeck JP (2003) MrBayes 3: Bayesian phylogenetic inference under mixed models. Bioinformatics 19:1572-1574. https://doi.org/10.1093/bioinformatics/btg180

Rosenthal LM, Larsson KH, Branco S, Chung JA, Glassman SI, Liao HL, Peay KG, Smith DP, Talbot JM, Taylor JW, Vellinga EC, Vilgalys R, Bruns TD (2017) Survey of corticioid fungi in North American pinaceous forests reveals hyperdiversity, underpopulated sequence databases, and species that are potentially ectomycorrhizal.
Mycologia 109:115-127. https://doi.org/10.1080/00275514.2017. 1281677

Species Fungorum (2019). http://www.speciesfungorum.org. Accessed 9 Nov 2019

Turland NJ, Wiersema JH, Barrie FR, Greuter W, Hawksworth DL, Herendeen PS, Knapp S, Kusber W-H, Li D-Z, Marhold K, May TW, McNeill J, Monro AM, Prado J, Price MJ, Smith GF (eds) (2018) International code of nomenclature for algae, fungi, and plants (Shenzhen code) adopted by the Nineteenth International Botanical Congress, Shenzhen, China, July 2017. Regnum Vegetabile 159. Glashütten: Koeltz Botanical Books. https://doi. org/10.12705/Code. 2018

Vilgalys R, Hester M (1990) Rapid genetic identification and mapping of enzymatically amplified ribosomal DNA from several Cryptococcus species. J Bacteriol 172:4238-4246. https://doi.org/10.1128/jb.172. 8.4238-4246.1990

Viner I, Spirin V, Zíbarová L, Larsson KH (2018) Additions to the taxonomy of Lagarobasidium and Xylodon (Hymenochaetales, Basidiomycota). MycoKeys 41:65-90. https://doi.org/10.3897/ mycokeys.41.28987

Vu D, Groenewald M, De Vries M, Gehrmann T, Stielow B, Eberhardt U, Al-Hatmi A, Groenewald JZ, Cardinali G, Houbraken J, Boekhout T, Crous PW, Robert V, Verkley GJM (2019) Large-scale generation and analysis of filamentous fungal DNA barcodes boosts coverage for kingdom fungi and reveals thresholds for fungal species and higher taxon delimitation. Stud Mycol 92:135-154. https://doi.org/ 10.1016/j.simyco.2018.05.001

Wang M, Chen YY (2017) Phylogeny and taxonomy of the genus Hyphodontia (Hymenochaetales, Basidiomycota) in China. Phytotaxa 309:45-54. https://doi.org/10.11646/phytotaxa.309.1.4

Wang Y, Lai Z, Li XX, Yan RM, Zhang ZB, Yang HL, Zhu D (2016) Isolation, diversity and acetylcholinesterase inhibitory activity of the culturable endophytic fungi harboured in Huperzia serrata from Jinggang Mountain, China. World J Microbiol Biotechnol 32:123. https://doi.org/10.1007/s11274-015-1966-3

White TJ, Bruns TD, Lee SB, Taylor JW (1990) Amplification and direct sequencing of fungal ribosomal RNA genes for phylogenetics. In: Innis MA, Gelfand DH, Sninsky JJ, White TJ (eds) PCR protocols: a guide to methods and applications. Academic Press, New York, pp 315-322

Wu SH (1990) The Corticiaceae (Basidiomycetes) subfamilies Phlebioideae, Phanerochaetoideae and Hyphodermoideae in Taiwan. Acta Bot Fenn 142:1-123

Xiong HX, Dai YC, Wu SH (2010) Two new species of Hyphodontia from China. Mycologia 102:918-922. https://doi.org/10.3852/09139

Yurchenko E, Kotiranta H (2007) Rare corticioid fungi (Basidiomycota, Aphyllophorales) from northern Belarus. Mycena 7:20-47

Yurchenko E, Wu SH (2014) Three new species of Hyphodontia with peg-like hyphal aggregations. Mycol Prog 13:533-545. https://doi. org/10.1007/s11557-013-0935-1

Yurchenko E, Riebesehl J, Langer E (2017) Clarification of Lyomyces sambuci complex with the descriptions of four new species. Mycol Prog 16:865-876. https://doi.org/10.1007/s11557-017-1321-1

Zhao CL, Cui BK, Dai YC (2014) Morphological and molecular identification of two new species of Hyphodontia (Schizoporaceae, Hymenochaetales) from southern China. Cryptogam Mycol 35: 87-97. https://doi.org/10.7872/crym.v35.iss1.2014.87

Publisher's note Springer Nature remains neutral with regard to jurisdictional claims in published maps and institutional affiliations. 